Article

\title{
Interfacial Compatibility Evaluation on the Fiber Treatment in the Typha Fiber Reinforced Epoxy Composites and Their Effect on the Chemical and Mechanical Properties
}

\author{
Samsul Rizal ${ }^{1}$, Ikramullah ${ }^{1, *}$, Deepu A. Gopakumar ${ }^{2}$, Sulaiman Thalib ${ }^{1}$, Syifaul Huzni ${ }^{1}$ and \\ H. P. S. Abdul Khalil 2,* \\ 1 Department of Mechanical Engineering, Faculty of Engineering, Universitas Syiah Kuala, Darussalam, \\ Banda Aceh 23111, Indonesia; samsul_r@yahoo.com (S.R.); sulaimanthalib@unsyiah.ac.id (S.T.); \\ syifaul@unsyiah.ac.id (S.H.) \\ 2 School of Industrial Technology, Universiti Sains Malaysia, Penang 11800, Malaysia; deepu1789@gmail.com \\ * Correspondence: ikramullah@mhs.unsyiah.ac.id (I.); akhalilhps@gmail.com (H.P.S.A.K.)
}

Received: 24 October 2018; Accepted: 21 November 2018; Published: 28 November 2018

\begin{abstract}
Natural fiber composites have been widely used for various applications such as automotive components, aircraft components and sports equipment. Among the natural fibers Typha spp have gained considerable attention to replace synthetic fibers due to their unique nature. The untreated and alkali-treated fibers treated in different durations were dried under the sun for $4 \mathrm{~h}$ prior to the fabrication of Typha fiber reinforced epoxy composites. The chemical structure and crystallinity index of composites were examined via FT-IR and XRD respectively. The tensile, flexural and impact tests were conducted to investigate the effect of the alkali treated Typha fibers on the epoxy composite. From the microscopy analysis, it was observed that the fracture mechanism of the composite was due to the fiber and matrix debonding, fiber pull out from the matrix, and fiber damage. The tensile, flexural and impact strength of the Typha fiber reinforced epoxy composite were increased after $5 \%$ alkaline immersion compared to untreated Typha fiber composite. From these results, it can be concluded that the alkali treatment on Typha fiber could improve the interfacial compatibility between epoxy resin and Typha fiber, which resulted in the better mechanical properties and made the composite more hydrophobic. So far there is no comprehensive report about Typha fiber reinforcing epoxy composite, investigating the effect of the alkali treatment duration on the interfacial compatibility, and their effect on chemical and mechanical of Typha fiber reinforced composite, which plays a vital role to provide the overall mechanical performance to the composite.
\end{abstract}

Keywords: Typha fiber; fiber treatment; wettability; epoxy composite; interfacial compatibility

\section{Introduction}

Since 1970 most fibers used in composites are synthetic fibers such as glass fibers, aramid, and carbon fibers because they have good mechanical properties [1]. However, synthetic fibers are not eco-friendly due to their non-biodegradable nature there by result in substantial environmental pollution. Therefore, the development of eco-friendly fiber reinforced composites has been attractive to scientists globally. Natural fibers are thought to be the solution to the problem because natural fibers are biodegradable and renewable. The development of several natural fiber composites using hemp, kenaf, coconut, sisal, banana, and pineapple apple fibers have been reported extensively [2,3] Natural fiber composites have been widely used for various applications such as automotive components, aircraft components and sports equipment [4]. The idea of using natural fiber as a reinforcer in a 
composite material is not something new. Humans have long used this idea, since the beginning of human civilization, grass and straw have been used to strengthen mud bricks. The use of natural fibers on composites can be cost-effective and light weight [5], another advantage possessed by natural fibers are their mechanical properties, which are not inferior to synthetic glass fibers that are often used as reinforcing fibers in composites [6]. One of the natural fibers that have the potential to replace synthetic fibers is Typha spp. Typha fibers are abundant in most countries [7]. Typha is very much grown on wetlands in the province of Aceh. This plant has been often considered a parasite because its growth dominates the wetlands. Although Typha is available abundantly in nature, its potential is still underutilized compared to other natural fibers [8]. From the previous reports it is well known that the Typha fiber reinforced composites have many advantages, such as good bending properties [9], being lightweight [10], having good mechanical strength, are low density and can be renewed [11]. However, so far there is no report about Typha fiber reinforcing epoxy composite. The objective of this paper was to investigate the effect of alkali treatment duration on the interfacial compatibility of the composite and their effect on mechanical and physical properties of Typha fiber reinforced composite, which plays a vital role to provide the overall mechanical performance to the composite.

In recent years, many studies have been aimed at developing biodegradable composites [12,13]. In last few decades, the natural fiber-reinforced polymer composites are starting to compete with synthetic fiber-reinforced composites such as glass fibers and carbon fibers because they have many advantages over glass fibers and carbon fibers [14]. Natural fibers have properties superior to glass fibers in terms of flexibility and stiffness [15]. Other advantages to be obtained from natural fibers compared to handmade and carbon fiber glass are their low cost, being low density and non-irritating to the skin, having reduced energy consumption, being renewable and biodegradable [16]. There are a variety of natural fibers that can be used to strengthen polymer composites, such as wood fibers, stem fibers, and leaf fibers. These fibers are widely available around the world [5].

\section{Materials and Methods}

\subsection{Materials}

Typha fibers were collected from swamps area in Darussalam, Aceh, Indonesia. Epoxy A331 and A062 hardener were obtained from Zarm Scientific Sdn. Bhd., Penang, Malaysia. Typha fiber was soaked with $5 \% \mathrm{NaOH}$ with differential immersion duration for $1 \mathrm{~h}, 2 \mathrm{~h}, 4 \mathrm{~h}$ and $8 \mathrm{~h}$.

\subsection{Composite Fabrication}

Typha fibers with $20 \mathrm{~mm}$ length were used as long fibers for reinforcement. The untreated and alkali-treated fibers in different treatment durations were dried under the sun for $4 \mathrm{~h}$ prior to the fabrication of epoxy composites. The epoxy composites were prepared in the molds with a dimension of $70 \mathrm{~mm} \times 15 \mathrm{~mm} \times 3 \mathrm{~mm}$ were cut by circular saw. Typha fibers of different dimensions were spread by polyester resin and epoxy by hand layup method with the composition of $40 \mathrm{wt} \%$ Typha fiber [17]. The molds were then pressed in compression molding machine at a pressure of $200 \mathrm{~kg} / \mathrm{cm}^{2}$. The composites were cured for $12 \mathrm{~h}$ at $100^{\circ} \mathrm{C}$.

\subsection{Chemical Composition}

To investigate the chemical composition of raw Typha fiber and Typha fiber epoxy composites, FTIR analysis has been done using Shimadzu IRPrestige-21 Fourier Transform Infrared Spectroscopy (FTIR) Shimadzu Corp., Kyoto, Japan).The peaks were recorded at a wavelength of 400 to $4000 \mathrm{~cm}^{-1}$. to study the functional group and phase of Typha fiber and Typha fiber composites. 


\subsection{Crystalline Structure}

In order to obtain the crystal structure, the wide-angle X-ray diffraction spectrum of the raw Typha fiber and Typha fiber epoxy composites were recorded on a Rigaku Dmax 2500 diffractometer (Rigaku Corp., Tokyo, Japan) The system has a rotating anode generator with a copper target and wide-angle powder goniometer. All samples were scanned in the $2 \theta$ range varying from $5^{\circ}$ to $50^{\circ}$.

\subsection{Tensile, Flexural and Impact Test}

The testing of tensile strength, ductility and modulus of Typha fiber reinforced composite were performed via tensile test machine using a MTS Landmark (MTS System Corp., Minnesota, USA) equipped with a load cell of $10 \mathrm{~N}$, with a cross-head speed of $2 \mathrm{~mm} / \mathrm{min}$ according to ASTM D638-02a. The flexural strength of the composite was tested according to ASTM D790-03. The impact test of composite was conducted according to ASTM D 256-97 by Ray-Ran test equipment.

\subsection{Morphology of the Composite}

The fractured surface of the composite was observed via Scanning Electron Microscope (Evo MA10, (Carl Zeiss, Oberkochen, Germany) after the impact test, in order to study the failure mechanism. The specimen was sputtered with gold before the operation. The composite samples were observed in the SEM at an acceleration voltage of $20 \mathrm{KV}$.

\subsection{Wettability}

The static water contact angle of the composite was measured via water drop method using KSV CAM 101 (KSV Instruments Ltd., Helsinki, Finland) optical contact angle meter to examine the surface wettability of the composite. Hypodermic syringes operated through micrometer screw control slowly dripped the water onto the composite surface. The contact angle was measured on the side of the water droplet. The image was recorded for $40 \mathrm{~s}$ with a speed of one frame every $10 \mathrm{~s}$.

\subsection{Interfacial Shear Strength Test}

The micro-bond test was performed to evaluate the interfacial shear strength of untreated and treated Typha fiber reinforced epoxy composite. A micro-droplet epoxy resin was dropped on Typha fibers with an embedded of length about 1.6-2.2 $\mathrm{mm}$ and fiber diameter of $0.2-0.5 \mathrm{~mm}$. After the epoxy was cured, the specimens were tested on a Hegewald \& Peschke inspect micro S500 (Hegewald \& Peschke, Nossen, Germany) or the tensile test. The blades were applied at the end of the matrix to hold the matrix, then the tip of the fiber was given the tensile load until the fiber was pulled out from the epoxy resin.

\section{Results and Discussion}

\subsection{FTIR and XRD Analysis of the Composites}

The FTIR spectrum of raw Typha fiber, untreated and treated Typha fiber reinforced epoxy composites are shown in Figure 1. From the figure, both Typha fiber and untreated Typha fiber reinforced epoxy composite show similar spectra. The peak that emerged at $897 \mathrm{~cm}^{-1}$ was assigned to the $\mathrm{C}-\mathrm{OH}$ denote the presence of $\beta$-glycosidic linkages between monosaccharides [18]. The peaks at 1247 and $1249 \mathrm{~cm}^{-1}$ were clearly seen in the spectra of raw Typha fiber and untreated Typha fiber reinforced epoxy composite respectively and which was due to the stretching of the $\mathrm{C}-\mathrm{O}$ functional group indicates possible alignment of lignin. This peak was no longer present on alkali-treated Typha reinforced epoxy composites. The strong bands at region between $3200-3600 \mathrm{~cm}^{-1}$ were due to the $\mathrm{O}-\mathrm{H}$ stretching [19], which were observed in all samples. The peak at $1735 \mathrm{~cm}^{-1} \mathrm{C}=\mathrm{O}$ from the stretching vibration of carboxylic acid and ester group of hemicellulose [20] appeared in both raw Typha fiber and untreated Typha fiber reinforced composite, where as in the alkali treated Typha fiber 
reinforced composites it disappeared due to the successful removal of the hemicellulose from alkali treated Typha fiber reinforced composites during the alkali treatment. From these results, it can be concluded that the alkali treatment had successfully removed the lignin and hemicellulose from the Typha fiber reinforced epoxy composite.

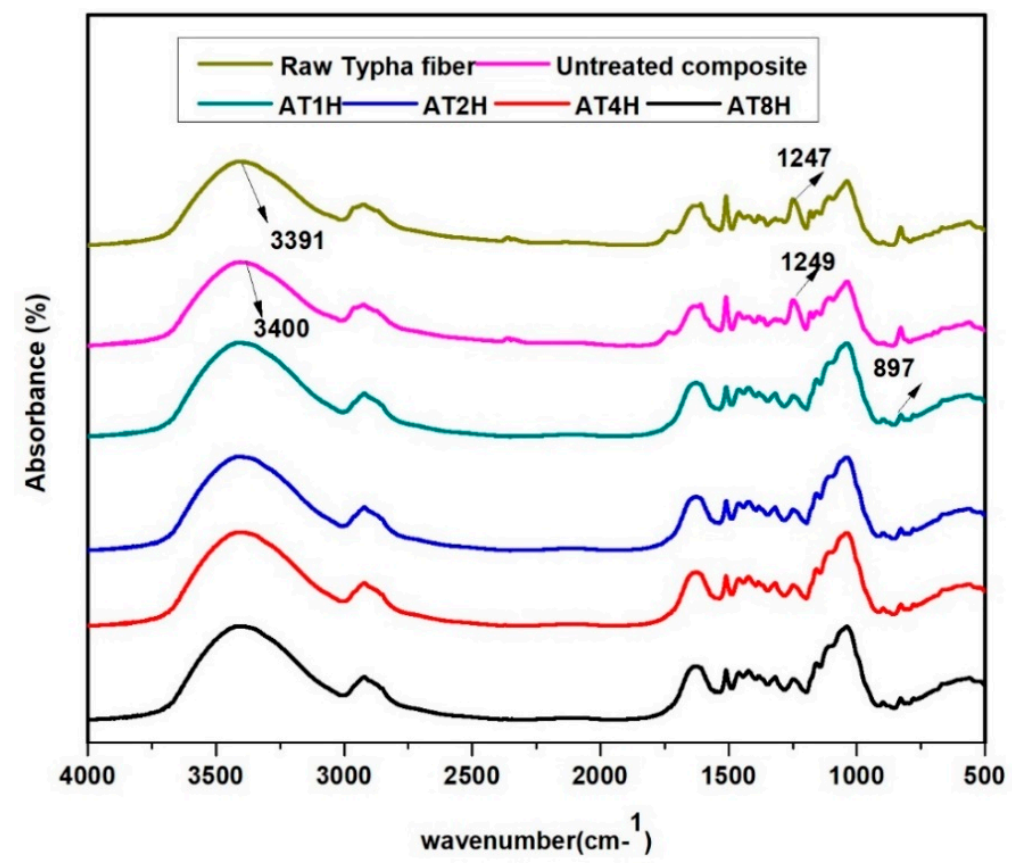

Figure 1. FTIR spectra of raw Typha fiber, untreated and treated Typha fiber reinforced epoxy composites.

The XRD analysis was conducted to investigate the crystallinity index of the raw Typha fiber, untreated Typha fiber reinforced epoxy composite and treated Typha fiber reinforced epoxy composites. X-Ray diffraction profiles of raw Typha fiber, untreated Typha fiber reinforced epoxy composite and treated Typha fiber reinforced epoxy composites are shown in Figure 2. The crystalline index was calculated by the Equation (1):

$$
\mathrm{CI}=\frac{I_{002}-I_{a m}}{I_{002}} \times 100
$$

The intensity of the raw Typha fiber and untreated Typha fiber reinforced epoxy composites was low as compared to the alkali treated Typha fiber reinforced epoxy composites. This was due to the fact that during the alkali treatment, the amorphous portions like hemicellulose and lignin were removed which resulted in the enhanced peak intensity for treated Typha fiber reinforced epoxy composites. The crystallinity index of raw Typha fiber and untreated Typha fiber reinforced epoxy composites was $32.7 \%$ and $37.5 \%$ respectively. Meanwhile, the crystallinity index of the composites which were reinforced with $5 \%$ alkali-treated Typha fiber with duration of 1, 2, 4 and 8-h were $42.9 \%, 43.8 \%, 44.2 \%$, and $36.5 \%$, respectively. It is well known that higher crystallinity will result in good mechanical properties. This enhanced crystallinity index in the Typha fiber reinforced epoxy composite was due to the removal of amorphous portions like hemicellulose and lignin from the Typha fibers during the alkali treatment. From these results, it can be concluded that the crystallinity index of the Typha fiber reinforced epoxy composite was increased after the 5\% alkaline treatment of the Typha fibers. 


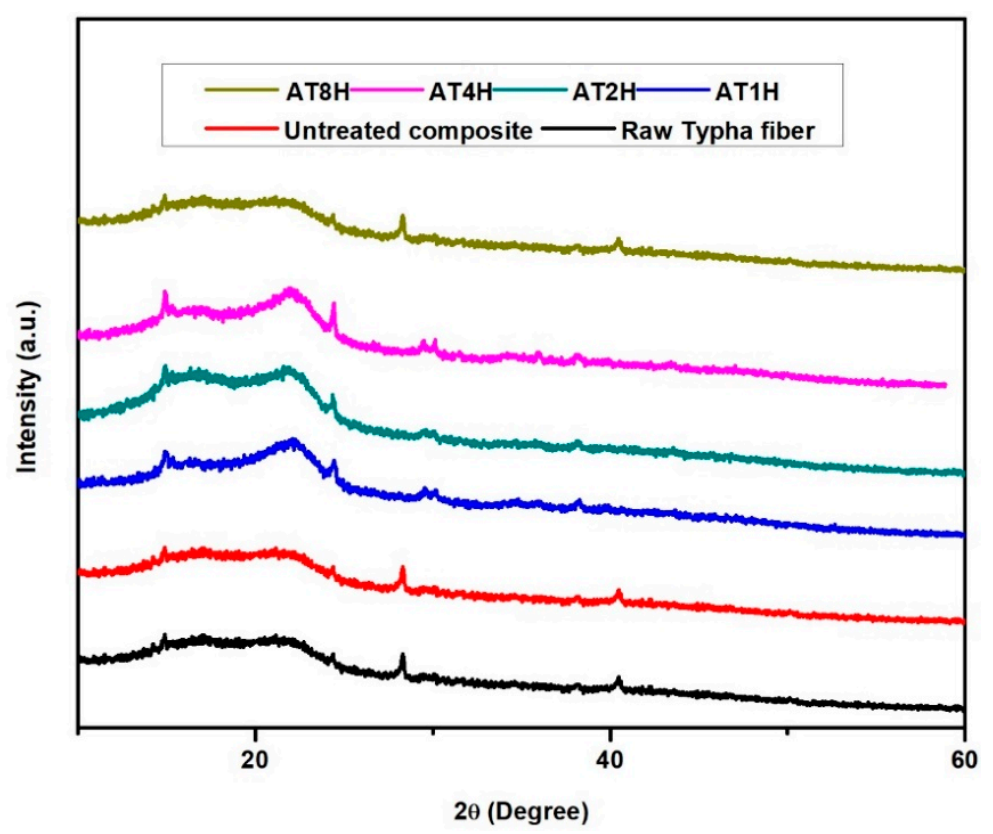

Figure 2. X-ray Diffraction patterns of raw Typha fiber, untreated and treated Typha fiber reinforced epoxy composites.

\subsection{Interfacial Shear Strength Evaluation of the Composites}

The interfacial shear strength of untreated and 5\% alkali treated Typha fiber reinforced epoxy composites are shown in Table 1. From Table 1, it is clearly shown that the average IFSS value for untreated Typha fiber reinforced epoxy composite was $2.24 \mathrm{MPa}$, whereas in the case of alkali treated Typha fiber reinforced epoxy composites, the value was higher than the untreated Typha fiber reinforced epoxy composite. The average IFSS value of alkali treated Typha fiber reinforced epoxy composites with treatment durations of 1, 2, 4 and $8 \mathrm{~h}$ were 2.718, 3.753, 3.96 and 4.185 MPa respectively. From these results, it can be concluded that the alkali-treated Typha fiber had good interface adhesion with the epoxy matrix when compared to untreated Typha fiber. This enhanced interface adhesion in alkali treated Typha fiber reinforced epoxy composite was due to the successful removal of amorphous portions like hemicellulose, lignin and pectin from the Typha fibers during the alkali treatment [18]. Epoxy resin could penetrate into the holes, valves and cracks of the alkali treated Typha fiber's surface which enables the mechanical interlocking of the epoxy matrix on the surface of the alkali treated Typha fiber, and thereby resulting in good bonding between the Typha fiber and epoxy matrix [19].

Table 1. Interfacial shear strength of untreated and treated Typha fiber reinforced epoxy composites.

\begin{tabular}{cc}
\hline Typha Fiber Reinforced Epoxy Composites & Interfacial Shear Strength (IFSS) Mpa \\
\hline Untreated & 2.24 \\
AT1H & 2.718 \\
AT2H & 3.753 \\
AT4H & 3.96 \\
AT8H & 4.185 \\
\hline
\end{tabular}

\subsection{Tensile Strength Analysis of the Composites}

Figure 3 shows the Typha fiber reinforced epoxy composite tensile strength and modulus, with the composition of $40 \mathrm{wt} \%$ Typha fiber. It can be observed from Figure 3 that the tensile strength and modulus of the Typha fiber reinforced epoxy composite were increased after 5\% alkaline immersion compared to untreated Typha fiber composite. Composite specimens with four hours of alkali treatment showed the highest tensile strength had a value of $37.4 \mathrm{MPa}$, while the untreated Typha composite 
only had 29.2 MPa. Similar studies have been reported by Cai et al. and they showed that the tensile strength of the composite were increased after the alkaline treatment of the fiber [18]. The researchers reported that the tensile behavior of composites, which were reinforced with alkali treated natural fibers, showed an enhancement in tensile strength and tensile modulus of the composites compared to natural fibers without the treatment $[20,21]$. Tensile strength and modulus increased proportionally with the duration of alkali treatment of fibers, but the tensile strength and modulus of composites displayed a significant decrease after an alkaline treatment of $8 \mathrm{~h}$. This was due to the degradation of cellulosic molecules after the prolonged treatment with alkali. The decline in the mechanical properties, especially the tensile strength and modulus of Typha fibers, was reported by our previous study, in which Typha fibers were damaged due to the prolonged treatment with $\mathrm{NaOH}$. During the alkali treatment, hemicellulose, lignin and pectin are successfully eliminated when the treatment proceeds from 1 to $8 \mathrm{~h}$. There was a decrement in the tensile strength of the alkali treated Typha fiber reinforced epoxy composites at $8 \mathrm{~h}$ of treatment. However, the interfacial shear strength (IFSS) between alkali treated Typha fibers and epoxy matrix increased (as given in Table 1), even at $8 \mathrm{~h}$ of alkali treatment, which was due to the mechanical interlocking of the epoxy matrix on the alkali treated Typha fiber, thereby resulting in the good bonding between the epoxy matrix and the alkali treated Typha fiber.
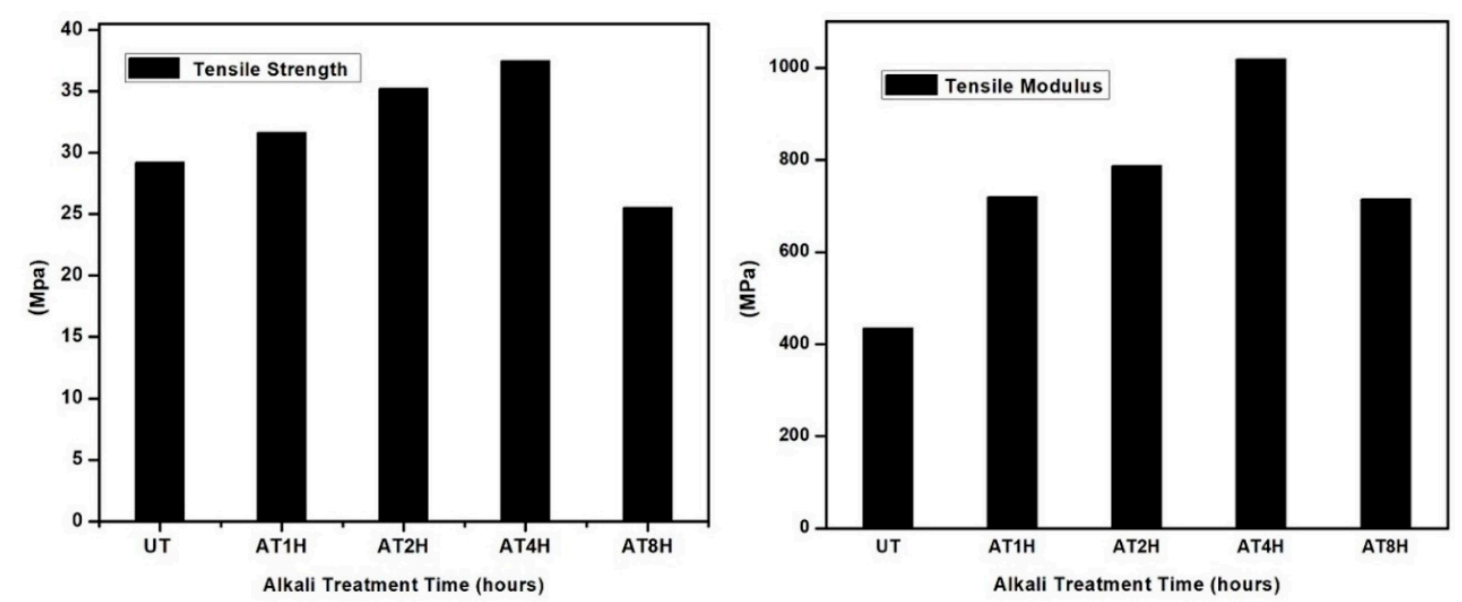

Figure 3. Tensile strength and Modulus of treated and untreated Typha fiber reinforced epoxy composite.

\subsection{Flexural Strength Analysis of Composites}

Figure 4 shows the flexural strength and flexural modulus of alkali treated Typha fiber reinforced epoxy composite and untreated Typha fiber reinforced epoxy composite. From the figure it was clear that the flexural strength of untreated Typha fiber reinforced epoxy composite was around $44.5 \mathrm{Mpa}$, where as in the incase of alkali treated Typha fiber reinforced epoxy composite, the flexural strength was 69.5, 77.2, 50.3 and 49.8 Mpa at varying durations of immersion in $\mathrm{NaOH}$ for 1, 2, 4 and $8 \mathrm{~h}$ respectively. From these results, it can be concluded that the untreated Typha fiber was not an effective reinforcement due to the poor interfacial compatibility between untreated Typha fiber and epoxy matrix. As expected, composites with $5 \% \mathrm{NaOH}$ treated Typha fiber have higher flexural strength than untreated Typha fiber composites, due to the removal of the amorphous portions like hemicellulose, lignin and wax from the Typha fibers during the alkali treatment and thereby resulting in the good interfacial compatibility between alkaline treated Typha fiber and epoxy matrix. This enhanced interfacial compatibility between the alkali treated Typha fiber and epoxy composite resulted in the enhanced flexural strength in the alkali treated Typha fiber reinforced epoxy composites, compared to the untreated Typha fiber reinforced epoxy composites. A similar observation was reported by Goud et al. and Boopathi et al., they reported that the enhancement in mechanical properties of composites was due to the good interfacial compatibility between the alkali treated fiber and matrix interface after the alkali treatment [22,23]. However, there was a decrease in the flexural strength for the $4 \mathrm{~h}$ alkaline treated composites. The decrease in flexural strength at the duration of alkali treatment 
for 4 and $8 \mathrm{~h}$ could be due to the degradation of the cellulose molecular structure during the prolonged treatment with the alkali, which resulted in the decreased flexural strength and flexural modulus of the composite [20,24].
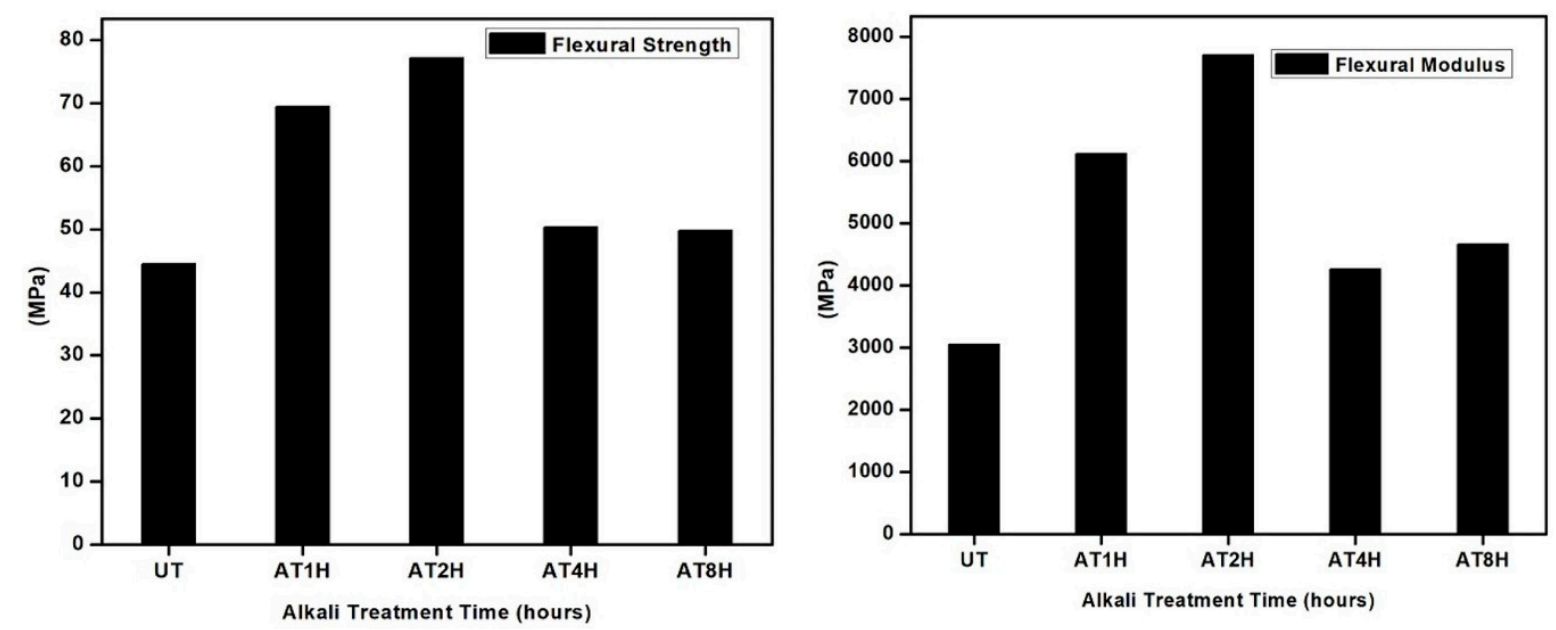

Figure 4. Flexural and Modulus Elasticity of untreated and treated Typha fiber reinforced epoxy composite.

\subsection{Impact Strength Analysis of Composites}

Alkaline-treated Typha fiber reinforced composites have better impact strength performance than untreated Typha fiber reinforced composites as shown in Figure 5. It was clearly shown that, the Typha fiber reinforced epoxy composite at 1 and $2 \mathrm{~h}$ alkali treated showed the highest impact strength of 12.4 and $14.2 \mathrm{KJ} / \mathrm{m}^{2}$ respectively. However, in the case of the Typha fiber reinforced epoxy composite at 4 and $8 \mathrm{~h}$, they showed a decrease in the impact strength of 12.8 and $12.8 \mathrm{KJ} / \mathrm{m}^{2}$ respectively. This decrease in the impact strength was due to the degradation of the cellular molecular structure during the prolonged alkaline treatment. The impact strength performance of natural fiber reinforced composites is mainly influenced by several main factors such as fiber properties, matrix properties, and fiber and matrix interface properties. The composites with weak interfacial compatibility can result in poor mechanical properties of the composite, which is due to crack propagation at the matrix interface. Weak interfacial compatibility in composites could accelerate matrix crack propagation and thereby result in the debonding of fibers and matrices. The fiber/matrix interface conditions might be also affected the energy absorption in the composite. If the composite has a good interfacial compatibility, the impact load received by the epoxy matrix could be transferred to the fiber. Therefore, the fiber plays a major role as a matrix reinforcement. The impact failure on the composite could be due to the fiber damage, matrix damage, fiber pull-out from the matrix and debonding between the fiber and matrix. When the load transferred to the fiber exceeds the fiber and matrix interface strength, debonding would occur [25]. From these results it can be concluded that, the presence of alkali treated Typha fiber could improve the interfacial compatibility between the epoxy resin and Typha fiber, and thereby enhance the impact strength of the epoxy resin. In this work, it was shown that epoxy resin becomes more resistant to impact loads after reinforcing with alkaline treated Typha fiber. The alkali treatment of the natural fiber could improve the impact strength of the epoxy matrix when compared to the carbon/fiber epoxy composite and glass/fiber epoxy composite as shown in Table 2. 


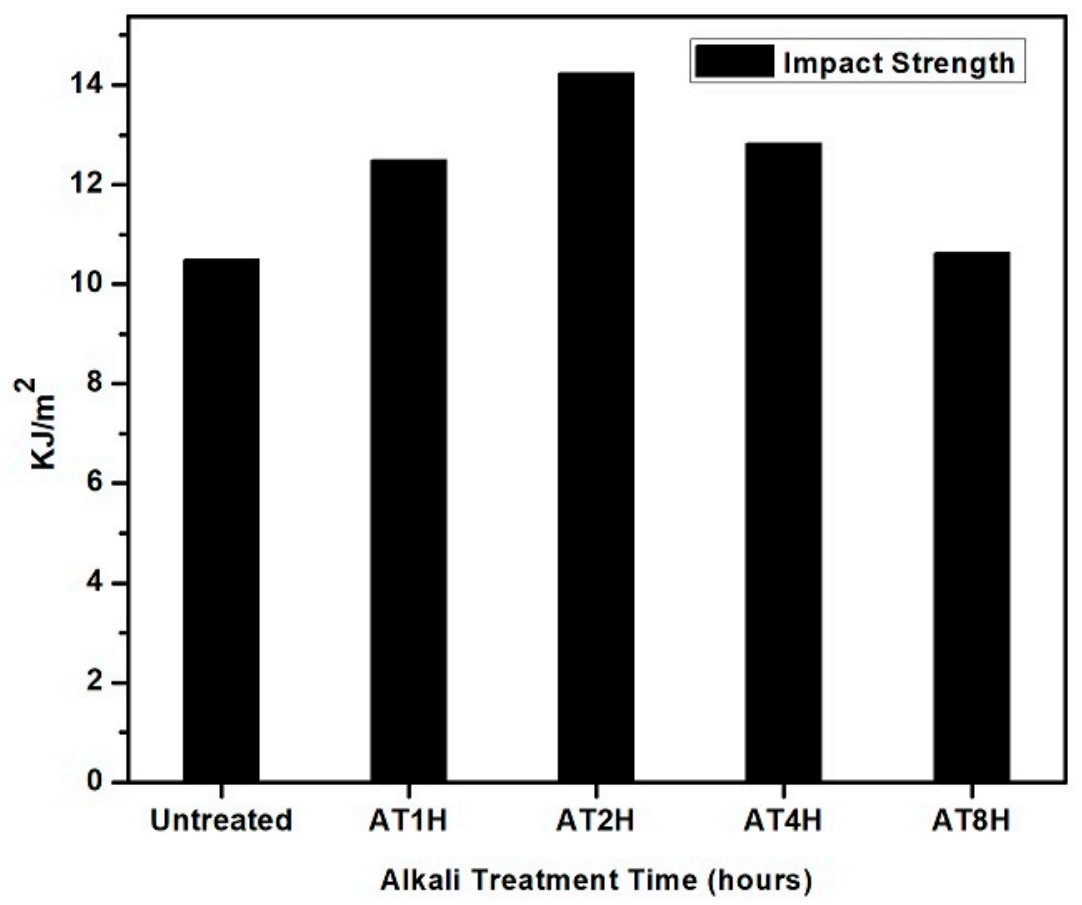

Figure 5. Impact strength of untreated and treated Typha fiber reinforced epoxy composite.

Table 2. Comparison of Mechanical properties of Typha reinforced epoxy fiber with carbon fiber/epoxy and glass fiber epoxy composites.

\begin{tabular}{ccccc}
\hline $\begin{array}{c}\text { Fiber/Epoxy } \\
\text { Composites }\end{array}$ & $\begin{array}{c}\text { Tensile } \\
\text { Strength (Mpa) }\end{array}$ & $\begin{array}{c}\text { Flexural } \\
\text { Strength (MPa) }\end{array}$ & $\begin{array}{c}\text { Impact } \\
\text { Strength }\end{array}$ & References \\
\hline Carbon fiber/epoxy & 329 & 525 & $0.4(\mathrm{~J} / \mathrm{m})$ & Rahmai et al. (2014) [26] \\
\hline Glass fiber/epoxy & 179 & 297 & $1.84(\mathrm{~J})$ & Sathishkumar et al. (2014) [27] \\
\hline Typha fiber/epoxy & 37 & 77 & $14 \mathrm{KJ} / \mathrm{m}^{2}$ & This work \\
\hline
\end{tabular}

\subsection{Scanning Electron Microscope Analysis}

Fractured surfaces of the specimens after impact testing were observed via scanning electron microscope to investigate the mechanism of the composite failure. Figure $6 a-c$ shows the SEM images of untreated Typha fibers. From the Figure $6 \mathrm{a}-\mathrm{c}$, it can be clearly seen that, a lot of fibers were pulled out from the untreated Typha fiber reinforced epoxy composite which resulted in the formation of the cavities in the epoxy matrix. This was due to the poor adhesion between untreated Typha fiber and the epoxy matrix. Failure of composites with untreated Typha fiber was caused due to the poor interface interaction between untreated Typha fiber and epoxy matrix. In contrast, as shown in the Figure $6 \mathrm{~d}$, the alkali-treated Typha fiber reinforced epoxy composites showed a good bonding of Typha fibers towards epoxy resin, which can be attributed to the good interfacial adhesion between the epoxy resin and alkali treated Typha fibers. Moreover, from Figure $6 \mathrm{~d}$, we could not find much fiber pull outs in alkali treated Typha fiber epoxy composites, which is also in good agreement with the better interfacial adhesion proposed between the alkali treated Typha fibers and epoxy resin. Fractured surfaces of the alkali treated Typha fiber reinforced epoxy composites with a duration of 2, 4 and $8 \mathrm{~h}$ of immersion in $5 \% \mathrm{NaOH}$, are shown in the Figure $6 \mathrm{~d}-\mathrm{f}$, respectively. From these images, it is clearly shown that the strong interfacial adhesion between alkali treated Typha fiber and epoxy resin resulted in the less fiber pull outs in the Figure 6d-f. In addition to that, the alkali treated Typha fibers were well embedded in the epoxy matrix, so that the load can be easily transferred from the epoxy matrix to the Typha fiber which resulted in the increased impact strength of the epoxy matrix [28]. Stress received by the matrix could be well distributed to the fiber when the interaction between the fiber and matrix becomes good, 
and thereby resulted in the enhanced mechanical properties of the composite. Alkali treatment has an important role in enhancing composite interfacial compatibility because during alkali treatment of Typha fibers, hemicellulose, lignin and wax were removed from the fibers which makes the surface of Typha fibers rougher. This increase in the roughness could be resulted in the good interaction between alkali treated Typha fibers and epoxy resin. Similar phenomenon was reported by Mylsamy et al. who observed the mechanical properties of the alkali treated agave reinforced epoxy composite [25]. They reported that alkali-treated agave fiber had better adhesion than the untreated one. From the microscopy analysis of the fractured surface alkali treated and untreated Typha fiber reinforced epoxy composites, it can be concluded that the failure of the Typha fiber reinforced epoxy composites was mainly due to the fiber and matrix debonding, fiber pull out from the matrix, and fiber damage.

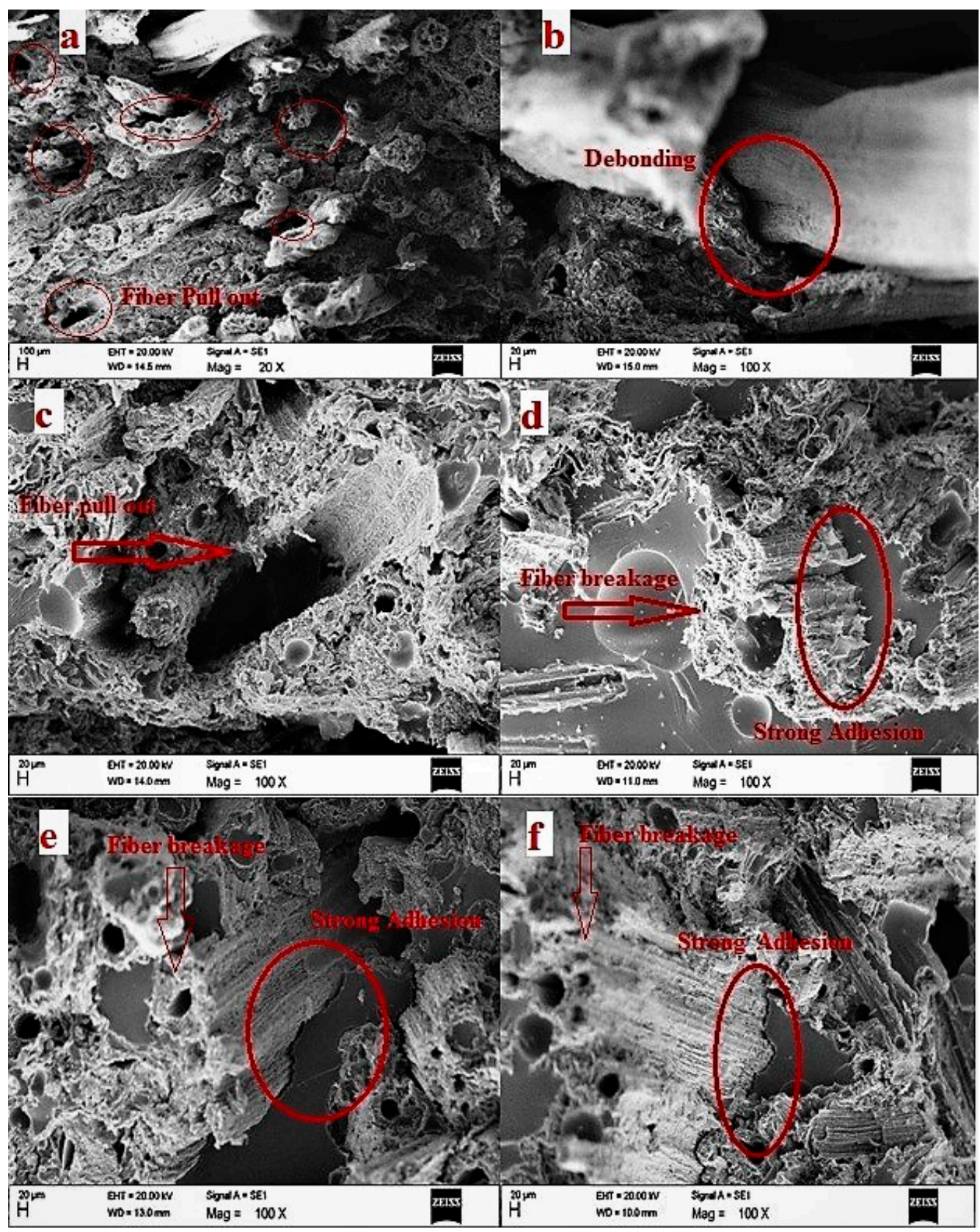

Figure 6. (a-c) shows the SEM images of untreated Typha fibers, $(\mathbf{d}-\mathbf{f})$ shows fractured surfaces of the alkali treated Typha fiber reinforced epoxy composites with a duration of 2, 4 and $8 \mathrm{~h}$ respectively. 


\subsection{Wettability Studies of the Composites}

Wettability of a liquid on a solid surface can be determined using contact angle measurements. The contact angle, $\theta$, is the angle formed by the liquid drop at the intersection point of the three-phase boundary between the plane tangent to the liquid and solid surface. A high value of $\theta$ indicates that the cohesive strength associated with bulk water is greater than the strength associated with the interaction of water with solid object surfaces, this indicates a weak interaction and poor wetting [29]. In contrast, low values of $\theta$, with spreading tendencies in solids show strong liquid-solid interactions [30]. This shows that the forces associated with the interaction of water with a surface are greater than the cohesive strength associated with bulk liquid water [29]. Figure 7 shows water contact angles of untreated and alkali-treated Typha fiber reinforced composites. Composites reinforced with 5\% alkaline-treated Typha fiber for one hour showed the highest contact angle of water at an angle of $87.50^{\circ}$, while the untreated composite showed the lowest contact angle. The enhancement in the contact angle for alkali treated composite was due to the enhanced surface roughness of the composite after alkali treatment [31]. The two main factors that influence the hydrophilicity of composites are surface roughness of fibers and accessibility of hydroxyl groups on the surface [32]. During alkali treatment, the hemicellulose, lignin and wax were removed which decreased the accessibility of hydroxyl groups. In addition to this, after alkali treatment the surface of the Typha fibers becomes rougher. This decreased accessibility of hydroxyl groups and enhanced surface roughness of the Typha fiber after alkali treatment resulted in the enhanced contact angle of alkali treated composite when compared to untreated one. From the contact angle studies of the treated and untreated Typha fiber composites, it can be concluded that the after-alkali treatment the Typha fiber composite became hydrophobic in nature.

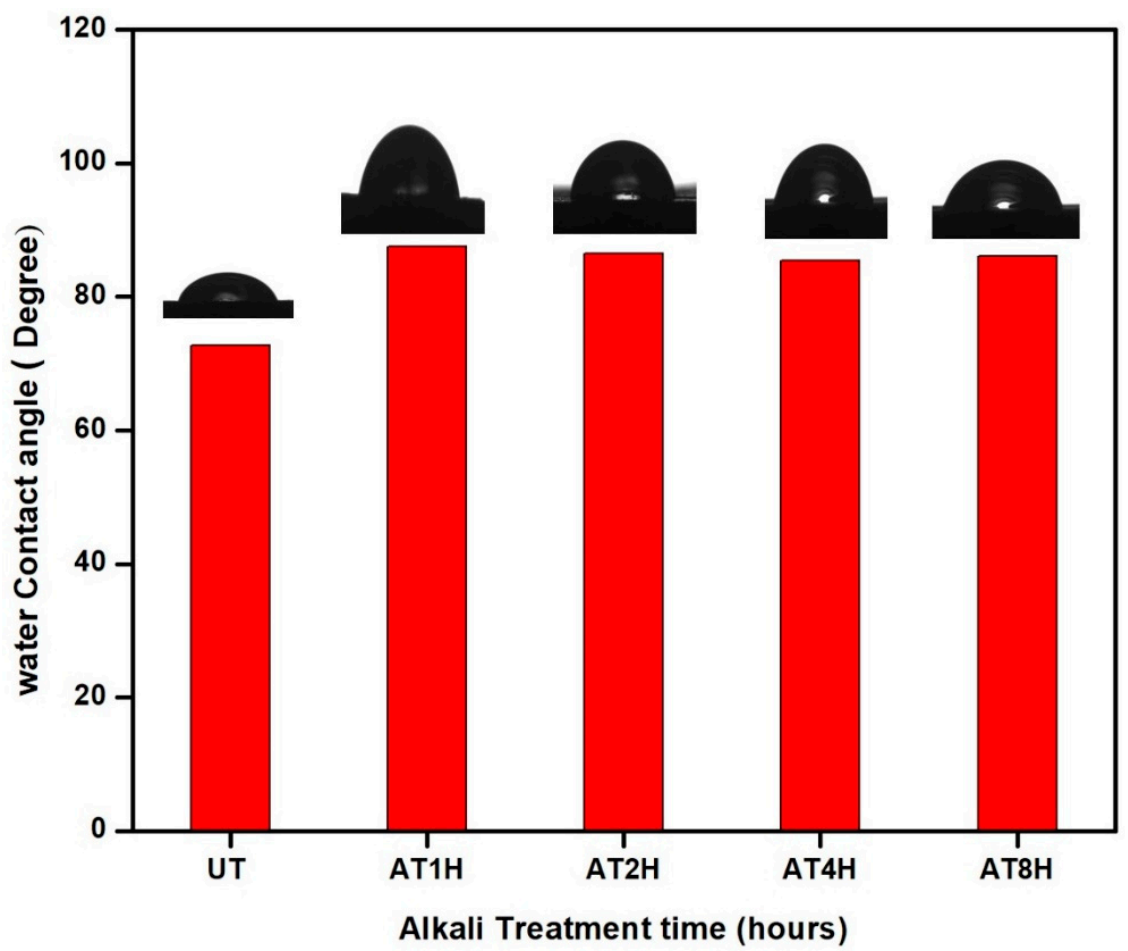

Figure 7. Contact angle of untreated and treated Typha fiber reinforced epoxy composite. 


\subsection{Thermal Analysis of the Composites}

The TGA and DTG curves of untreated and treated Typha fiber reinforced epoxy composites are shown in the Figure 8, which clearly describes the decomposition temperature and thermal stability of the composites throughout the various duration of $5 \%$ alkali treatment. From the Figure 8 , it was clearly seen that, the initial decomposition temperature ( $\left.T_{\text {onset }}\right)$ of untreated, 1, 2, 4 and $8 \mathrm{~h}$ alkali treated Typha fiber reinforced epoxy composites were found to be $244,246,258,261$, and $242{ }^{\circ} \mathrm{C}$, respectively.

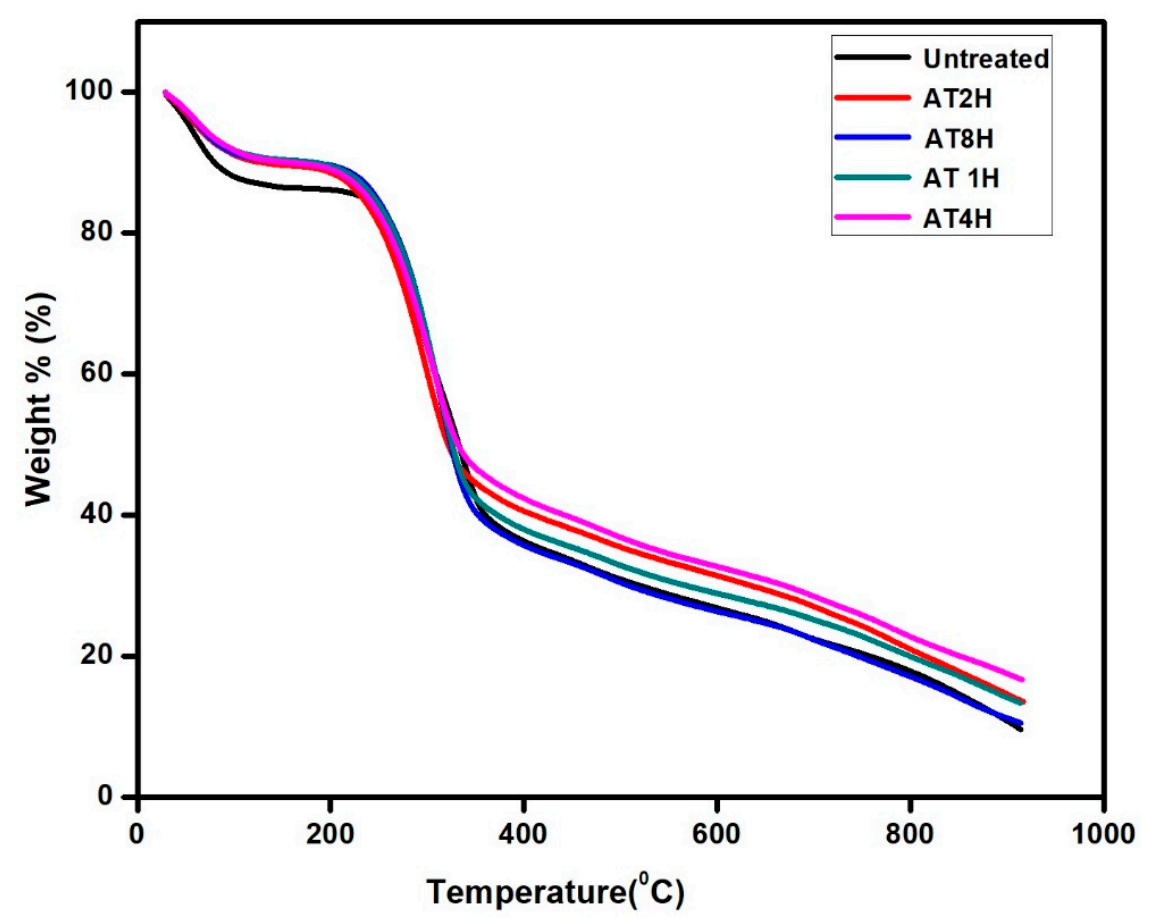

Figure 8. TGA curves of untreated and treated Typha fiber reinforced epoxy composites.

There was an enhancement in the initial degradation temperature of the composites reinforced with the alkali treated Typha fibers compared to the untreated Typha fiber reinforced epoxy composites, due to the removal of the amorphous portions from the Typha fiber during the alkali treatment. Furthermore, the value of maximum degradation temperature $\left(T_{\max }\right)$ of untreated, 1, 2, 4 and $8 \mathrm{~h}$ alkali treated Typha fiber reinforced epoxy composites were $314,438,443,445$ and $435{ }^{\circ} \mathrm{C}$, respectively. The composite treated with the $4 \mathrm{~h}$ alkali treatment showed the highest $T_{\max }$ values which was due to the highly crystalline nature of the samples. The composite treated with $4 \mathrm{~h}$ alkali treatment had the higher crystallinity index value of $44.2 \%$ which was higher than all the other samples, resulted in the higher thermal stability compared to the other composites. Among the alkali treated samples, the composite treated with $8 \mathrm{~h}$ alkali treatment showed low thermal stability which was due to the degradation of the cellulose molecules during the prolonged treatment with alkali. This resulted in the low thermal stability and crystallinity index (36.5\%) of the composites treated with the $8 \mathrm{~h}$ alkali treatment. From this thermogravimetric analysis of the treated and untreated Typha fiber reinforced epoxy composites data, it can be concluded that the composite treated with $4 \mathrm{~h}$ alkali treatment had very good thermal stability due to its high crystalline nature compared to other composites.

\section{Conclusions}

A series of alkali treated Typha fiber reinforced epoxy composites were fabricated via a hand layup method. Alkali treatment had been successfully done on the Typha fibers by immersing Typha fibers in $5 \% \mathrm{NaOH}$ for 1, 2, 4 and $8 \mathrm{~h}$. From the XRD and FTIR analysis, it can be concluded that the alkali treatment had been successfully removed the lignin and hemicellulose from Typha fiber reinforced epoxy composite and converted the amorphous Typha fiber into a crystalline form. 
The tensile, flexural, interfacial shear strength and impact strength of the Typha fiber reinforced epoxy composite were increased after 5\% alkali immersion, compared to untreated Typha fiber composite. The enhancement in the mechanical properties of the alkali treated Typha fiber reinforced epoxy composite was due to the better interfacial compatibility between the alkali treated Typha fiber and epoxy resin. Wettability studies revealed that the alkali treated Typha fiber reinforced epoxy composites become more hydrophobic than the untreated one. This enhancement in contact angle for the alkali treated composite was due to the enhanced surface roughness and decreased accessibility of hydroxyl groups after the alkaline treatment. The failure mechanism of Typha fiber-reinforced composites was due to fiber and matrix debonding, fiber pull out from the matrix, and fiber damage. From these results it can be concluded that the alkali treatment on Typha fiber could improve interfacial compatibility between epoxy resin and Typha fiber, which results in better mechanical composite performance by making the composite more hydrophobic. We firmly believe that the demonstrated robust hydrophobic alkali treated Typha fiber reinforced epoxy composite will be a promising candidate for the various applications such as automotive components, aircraft components and sports equipment.

Author Contributions: Conceptualization, H.P.S.A.K., and S.R.; Methodology, I. Software, D.A.G.; Validation, I., S.T. and S.H. Formal Analysis, I.; Investigation, I.; Resources, S.T.; Data Curation, S.H.; Writing-Original draft Preparation, I.; Writing-Review and Editing, D.A.G.; Visualization, S.R.; Supervision, H.P.S.A.K.; Project Administration, S.R. and H.P.S.A.K.; Funding Acquisition, S.R.

Funding: This work was supported by Ministry Research, Technology and Higher Education of Republic of Indonesia by World Class Professor (WCP), Program scheme No 123.5/D2.3/KP/2018 and Program Magister Menuju Doktor untuk Sarjana Unggul (PMDSU).

Conflicts of Interest: The authors declare no conflict of interest.

\section{References}

1. Dedeepya, M.; Raju, T.D.; Kumar, T.J. Effect of Alkaline Treatment on Mechanical and Thermal Properties Oftypha Angustifolia Fiber Reinforced Composites. Int. J. Mech. Ind. Eng. 2012, 1, 12-14.

2. Faruk, O.; Bledzki, A.K.; Fink, H.P.; Sain, M. Biocomposites reinforced with natural fibers: 2000-2010. Prog. Polym. Sci. 2012, 37, 1552-1596. [CrossRef]

3. Li, X.; Tabil, L.G.; Panigrahi, S.; Crerar, W.J. The Influence of Fiber Content on Properties of Injection Molded Flax Fiber-HDPE Biocomposites. In Proceedings of the 2006 CSBE/SCGAB, Edmonton, AB, Canada, 16-19 July 2006. [CrossRef]

4. Pil, L.; Bensadoun, F.; Pariset, J.; Verpoest, I. Why are designers fascinated by flax and hemp fibre composites? Compos. Part A Appl. Sci. Manuf. 2016, 83, 193-205. [CrossRef]

5. Sanjay, M.R.; Arpitha, G.R.; Yogesha, B. Study on Mechanical Properties of Natural-Glass Fibre Reinforced Polymer Hybrid Composites: A Review. Mater. Today Proc. 2015, 2, 2959-2967. [CrossRef]

6. Sliseris, J.; Yan, L.; Kasal, B. Numerical modelling of flax short fibre reinforced and flax fibre fabric reinforced polymer composites. Compos. Part B Eng. 2016, 89, 143-154. [CrossRef]

7. Baldwin, B.; Cannon, A. Typha Review; Utah State University: Logan, UT, USA, 2007.

8. Ramanaiah, K.; Ratna Prasad, A.V.; Chandra Reddy, K.H. Mechanical Properties and Thermal Conductivity of Typha angustifolia Natural Fiber-Reinforced Polyester Composites. Int. J. Polym. Anal. Charact. 2011, 16, 496-503. [CrossRef]

9. Bajwa, D.S.; Sitz, E.D.; Bajwa, S.G.; Barnick, A.R. Evaluation of cattail (Typha spp.) for manufacturing composite panels. Ind. Crops Prod. 2015, 75, 195-199. [CrossRef]

10. Wuzella, G.; Mahendran, A.R.; Bätge, T.; Jury, S.; Kandelbauer, A. Novel, binder-free fiber reinforced composites based on a renewable resource from the reed-like plant Typha sp. Ind. Crops Prod. 2011, 33, 683-689. [CrossRef]

11. Ponnukrishnan, P.; Chithambara, T.M.; Richard, S. Mechanical Charactreisation of Typha Domingensis. Am. Int. J. Res. Sci. Technol. Eng. Math. 2014, 6, 241-244.

12. Saba, N.; Paridah, M.T.; Jawaid, M. Mechanical properties of kenaf fibre reinforced polymer composite: A review. Constr. Build. Mater. 2015, 76, 87-96. [CrossRef] 
13. Gurunathan, T.; Mohanty, S.; Nayak, S.K. A review of the recent developments in biocomposites based on natural fibres and their application perspectives. Compos. Part A Appl. Sci. Manuf. 2015, 77, 1-25. [CrossRef]

14. Saheb, D.N.; Jog, J.P. Natural Fiber Polymer Composites: A Review. Adv. Polym. Technol. 1999, 18, $351-363$. [CrossRef]

15. Jarukumjorn, K.; Suppakarn, N. Effect of glass fiber hybridization on properties of sisal fiber-polypropylene composites. Compos. Part B Eng. 2009, 40, 623-627. [CrossRef]

16. Malkapuram, R.; Kumar, V.; Yuvraj Singh Negi, Y.S. Recent Development in Natural Fiber Reinforced Polypropylene Composites. J. Reinf. Plast. Compos. 2009, 28, 1169-1189. [CrossRef]

17. Haghdan, S.; Smith, G.D. Natural fiber reinforced polyester composites: A literature review. J. Reinf. Plast. Compos. 2015, 34, 1179-1190. [CrossRef]

18. Cai, M.; Takagi, H.; Nakagaito, A.N.; Li, Y.; Waterhouse, G.I.N. Effect of alkali treatment on interfacial bonding in abaca fiber-reinforced composites. Compos. Part A Appl. Sci. Manuf. 2016, 90, 589-597. [CrossRef]

19. Zhou, Y.; Fan, M.; Chen, L. Interface and bonding mechanisms of plant fibre composites: An overview. Compos. Part B Eng. 2016, 101, 31-45. [CrossRef]

20. Manalo, A.C.; Wani, E.; Zukarnain, N.A.; Karunasena, W.; Lau, K.T. Effects of alkali treatment and elevated temperature on the mechanical properties of bamboo fibre-polyester composites. Compos. Part B Eng. 2015, 80, 73-83. [CrossRef]

21. El-Abbassi, F.E.; Assarar, M.; Ayad, R.; Lamdouar, N. Effect of alkali treatment on Alfa fibre as reinforcement for polypropylene based eco-composites: Mechanical behaviour and water ageing. Compos. Struct. 2015, 133, 451-457. [CrossRef]

22. Goud, G.; Rao, R.N. Effect of fibre content and alkali treatment on mechanical properties of Roystonea regia-reinforced epoxy partially biodegradable composites. Bull. Mater. Sci. 2011, 34, 1575-1581. [CrossRef]

23. Boopathi, L.; Sampath, P.S.; Mylsamy, K. Investigation of physical, chemical and mechanical properties of raw and alkali treated Borassus fruit fiber. Compos. Part B Eng. 2012, 43, 3044-3052. [CrossRef]

24. Obi Reddy, K.; Uma Maheswari, C.; Shukla, M.; Song, J.I.; Varada Rajulu, A. Tensile and structural characterization of alkali treated Borassus fruit fine fibers. Compos. Part B Eng. 2013, 44, 433-438. [CrossRef]

25. Mylsamy, K.; Rajendran, I. Influence of alkali treatment and fibre length on mechanical properties of short Agave fibre reinforced epoxy composites. Mater. Des. 2011, 32, 4629-4640. [CrossRef]

26. Rahmani, H.; Najafi, S.H.M.; Ashori, A. Mechanical performance of epoxy/carbon fiber laminated composites. J. Reinf. Plast. Compos. 2014, 33, 733-740. [CrossRef]

27. Sathishkumar, T.P.; Naveen, J.; Satheeshkumar, S. Hybrid fiber reinforced polymer composites-A review. J. Reinf. Plast. Compos. 2014, 33, 454-471. [CrossRef]

28. Khan, Z.; Yousif, B.F.; Islam, M. Fracture behaviour of bamboo fiber reinforced epoxy composites. Compos. Part B Eng. 2017, 116, 186-199. [CrossRef]

29. Arkles, B.; Pan, Y. Hydrophobicity, Hydrophilicity and Silane Surface Modification; Gelest Inc.: Morrisville, PA, USA, 2011.

30. Ucar, I.O.; Cansoy, C.E.; Erbil, H.Y.; Pettitt, M.E.; Callow, M.E.; Callow, J.A. Effect of contact angle hysteresis on the removal of the sporelings of the green alga Ulva from the fouling-release coatings synthesized from polyolefin polymers. Biointerphases 2010, 5, 75-84. [CrossRef] [PubMed]

31. Chen, H.; Zhang, W.; Wang, X.; Wang, H.; Wu, Y.; Zhong, T.; Fei, B. Effect of alkali treatment on wettability and thermal stability of individual bamboo fibers. J. Wood Sci. 2018, 64, 398-405. [CrossRef]

32. Chowdhury, M.N.K.; Beg, M.D.H.; Khan, M.R.; Mina, M.F. Modification of oil palm empty fruit bunch fibers by nanoparticle impregnation and alkali treatment. Cellulose 2013, 20, 1477-1490. [CrossRef]

(C) 2018 by the authors. Licensee MDPI, Basel, Switzerland. This article is an open access article distributed under the terms and conditions of the Creative Commons Attribution (CC BY) license (http://creativecommons.org/licenses/by/4.0/). 